\title{
NAMES AND COLLECTIVE IDENTITY
}

\author{
OTTO KROGSETH \\ University of Oslo
}

\section{A B S T R ACT}

The preceding two decades have displayed a remarkable awareness for a connection between the concepts "identity" and "cultural memory". David Lowenthal speaks of a "current craze for heritage"! Cultural heritage has become extremely popular, especially in combination with tourism, and has accordingly been converted into a modern system of meaning - a type of "secular religion". With reference to collective identity and cultural memory, it is important to ask the cultural analytical questions: "Why identity now? Why heritage now?" My reply is that we experience a critical identity crisis. Three central aspects signify individual and collective identity: Continuity, coherence and individuality. The three aspects, constituting the concept of identity, are exposed to serious threats in the post-modern era: The danger of changeability, fragmentation and standardisation. This tendency has, however, met various compensating counter reactions like for instance "re-traditionalisation". In my presentation, I will examine the phenomenon cultural memory through examples from the German tradition principally from the works of Aleida and Jan Assmann.

\section{[1] INTRODUCTION}

This article may be more about identity than about names and naming, but I hope and believe that collective and cultural identity thematics will be shown to have a clear relevance to naming thematics.

My own primary fields of interest are those perspectives of identity thematics which are linked to cultural analysis and diagnostics of the present. Over the past couple of decades we have witnessed a virtually explosive increase of interest in various aspects of collective and cultural identity thematics. A central aspect here is the interest in cultural heritage and cultural rememberance, or collective foundation in tradition. Why this intense interest right now, is my question for diagnosing the present.

I shall provide the answer immediately: the strong interest in cultural and collective identity is the product of an identity crisis - a result of, and an answer to, the confusion of identity and the disintegration of sources of identity in the late modern cultural situation. This is for instance the diagnosis of the cultural sociologist Zygmunt Bauman, and it is also my own. The strong involvement in cultural heritage and cultural foundation and rememberance I see as attempts 
at compensatory and restorative emergency treatment of identity threatened by dissolution.

\section{[2] IDENTITY - WHAT IS THAT?}

Then what is identity? In Pluralisme og identitet (Henriksen \& Krogseth 2001) I operate with three criteria or main aspects of late modern (or postmodern) identity. The contextual and cultural frames of reference surrounding identity are emphasised by allowing each of the three criteria to be challenged or threatened by a topical counterpart.

The first criterion of identity is constancy or continuity through time. Here the counterpart or counter-concept is changeability. In spite of the accelerating changeability of the present time, there are hardly grounds for perceiving our identity or personality as totally changeable, something must be constant. When I look at my own confirmation photo, it can hardly be a total stranger whom I am trying to recognise fifty years later? Or when we make promises, especially long term promises (for instance marriage vows). In a certain sense, the person making the promise is surely the same as the one feeling bound by the promise twenty, thirty or forty years later? Otherwise, it would hardly be possible to make such promises?

The second criterion is identity as integrity or inner coherence. Here the counterconcept is fragmentation or disintegration. In spite of all (modern) pluralisation, differentiation and segmentation, most of us feel that we somehow hang together, albeit not always in a well-integrated way. Somewhere we carry and anchor all the contradictory roles imposed on us by modern life. We are not "multiple selves".

The third criterion is identity as individuality or personal character. Here the counter-concept is conformity or homogenisation, for instance as a result of globalisation or other forms of cultural uniformity. Who am I, as opposed to others? Individuality is here confirmed in spite of, often as a protest against, the threat of conformity, often in the form of pronounced demonstration of differences.

The counter positions of the three criteria of identity are so important because they show how radically the formation of identity has been made difficult in the specifically (post)modern cultural context. Perhaps we do not "have" constancy of identity, integrity and distinctive character - as something given and firmly existing? Identity is perhaps only a mental construction, on the basis of (compensatory) needs and wishes? Perhaps the identity sceptics are right when they claim that our identity is nothing but illusion and wishful thinking? We probably have exaggerated ideas of the continuity of the ego, says Peter Berger - perhaps the continuity is only held in place by the thin thread of memory? Perhaps integrity as well is nothing but an expression of a psychological urge to perceive oneself as a whole? 
Modern identity, then, is fundamentally threatened. The consequence of this is that it has to receive compensatory emergency treatment, for instance through (re)sacralisation and (re)historicisation. Perhaps we may refer to a double deficiency of modern identity: It is both understimulated as a result of loss of meaning, and also fragmentated and confused as a result of increased pluralisation and differentiation. The flicker effect of consumer, media and market culture also contributes with its identity-disrupting cultural influence.

These different identity conditions in the postmodern cultural context make it impossible to talk about identity as a constant, essential core identity. Instead, it is rather described as an individualised, continually reflexively reconstructed and retold project identity. Nomadic, chameleonic, latticework or palimpsest identity are other frequently used expressions.

\section{[3] CULTURAL AND COLLECTIVE IDENTITY}

So far the primary focus has been identity on individual terms, although the current cultural context has also been mentioned. Then what is collective identity?

It should be specified right away: Individual and collective identity are not different things. Identity is never exclusively individual, not even with a hermite or a Robinson Crusoe. Besides, when we talk of collective - or social or cultural - identity, it is a "personal matter", it is individually and existentially founded. It is true that one also refers to collective identity on "collective terms", as the collective's own identity independent of personal foundation or individual identification. It makes perfect sense to talk of the identity of a collective institution - the subject of onomastics may have its identity, just like the Labour Party or the Norwegian School of Theology may have theirs, etc. We may even refer to the "soul" of an institution to emphasise its distinctive character and inner essence.

However, what happens when we thus interpret collective identity on collectivistic terms, is that we make an analogical transfer from the individual sphere. Such an analogical transfer may under certain conditions be justified. It makes sense to transfer all the three criteria of identity to collective institutions and groupings, as long as one realises the dangers of transference, for instance in the direction of hypostasis or quasi-personalisation. Still, it is of course perfectly possible to attribute to a collective (greater or lesser) continuity through its history, (greater or lesser) integrity or inner coherence - for instance through the ideological basis or objects clause, or (greater or lesser) individuality and distinctive character. It is also perfectly possible and meaningful - and it is being done continually - to transfer individual qualities, such as disease and health, crisis and harmony, to the collective sphere.

In conclusion I will claim that even though we continually come across definitions of collective identity in the sense of the collective's own identity, the individually collective sense is the primary and original one. Collective identity per- 
ceived as the individual's (more or less conscious and reflective) identification of the collective also contains the element of existential and reflexive relationship inherent in the concept of identity. That this individually collective usage erases the distinction between individual and collective identity, is a problem we just have to live with.

Such a collective identity or identification of community may be illustrated by different models. The most well-known one is probably the concentric circle model, where increasingly wide circles are drawn around the individual: close family, extended family, local community, town/suburb, region, nation etc. Another model is the sector or area model, where the individual identifies with a sector of the community - this may be by virtue of gender or sexual identity, class or professional identity, ethnic or religious identity, leisure or lifestyle identity etc.

\section{[4] NAME AND IDENTITY}

Collective identity, then, is identity perceived as the individual's identification with the community. The phenomenon of names and naming may also be perceived as such an identity-building collective identification. "Naming", says Derek Alderman, "is a powerful vehicle for promoting identification with the past and locating oneself within networks of memory" (Alderman 2008, 195). The surname or family name includes us - especially when it is based on a farm name or a placename - in a continuity-forming and hence identity-shaping context. So can the first name, for that matter, when children are named for parents and ancestors, but it is still primarily the family name that has this collective identity function. Furthermore, it can also be said that the combination of first name and surname has the individualising and distinctively characterising function which also is part of our identity. Our name is an identity badge or an identity marker which helps us - for ourselves and by others - to be identified as the same person, as identical. It also fills an important double function of being both individual and collective, unique (at least relatively so) and founded in community.

The topic of foundation in family could also inspire further reflection on names, and on identity based on locality or tradition. Genealogy - with its starting point in names - is after all an exciting "archeological" work of excavation where ever new palimpsest levels of our identity are uncovered, and where ever new identitymaking stories are topicalised. Here, foundation in locality, in the ancestral farm, the parish, the place of origin, also plays its part as an important collectively identity-making factor. The locality, the limited space, gives integration in a community (the integratedness aspect of identity) and foundation in tradition (the continuity aspect), and the place name and the uniqueness of the place (or origin) also marks distinctive character - or the individuality aspect of identity. 
Even though the identity-confirming, conservatory and collectively identifying force of naming must probably be emphasised as the most central function, it should still not be perceived as the only one. Naming, of both families and places, may also be part of other ideological contexts of interest. Names may also be changed and create discontinuity rather than continuity, disruption rather than stability. That may apply on the individual level in connection with the change of surname because of marriage, and it may apply on the collective level in connection with renaming of place names. Here marginalisation and oppression, conflicts and territorial discords of interest (e.g. in relation to the territories of indigenous peoples) may also come into play. This is also valid in connection with the identity function of cultural heritage. The way in which cultural memory links the past to the present is very much an "ideologically driven process", according to Derek Alderman (Alderman 2008, 199).

\section{[5] CULTURAL HERITAgE AND CULTURAL MEMORY}

The named ancestral home gives "space" for shared identity-making memory on material as well as symbolic-mental terms. The place or space emerges as something more stable and safely accessible than the floating changeability of time. The places of memory evoke the remains of earlier experiences, making tradition and the past visible and present. They also tend to become the sites of ritual feasts, celebrations and anniversaries, or of mythifying stories of origin, filling them with mnemonic energy and sacralisation.

Mythified and sacralised places of memory are also a central topic in cultural heritage and cultural memory. As mentioned initially, I see the current "craze for heritage" (Lowenthal 1985) as a culture-analytically particularly interesting aspect of our era's compensatory cultivation of identity. Accelerating changeability and fragmentation in contemporary culture has created a crisis of memory and identity characterised by a new problematic relationship to time and foundation in tradition (Bauman 2000). The lack of master narratives and perspectives of continuity to link the past and the present in an identity-making and meaningful way challenges cultural scholars to establish new and different perspectives of impartation and topicalisation regarding tradition and experiences of the past (different from the objectivist, disruptive and continuity-weakening historical research). Central theoreticians of cultural heritage point out that we are currently in a "post-historical paradoxical situation" of both ahistoricity and rehistoricalisation, loss of tradition and re-traditionalisation, oblivion and "museummania", amnesia and "memory-boom" (Lowenthal 1985; Huyssen 1995, etc.).

Cultural heritage and cultural memory are about our relationship to the past, and the significance of the past to the present. It is a matter of imparting a heritage as vividly as possible, of establishing new links - creating continuity and making identity - to past experiences. The contemporary interest in cultural 
heritage, retraditionalisation and "back to the roots" tendencies in general, are the response to acute needs for cultural compensation, to a development which uproots, divides and uniforms us. The cultivation of the past and of cultural heritage emerges as an acutely necessary basis for identity.

\title{
REFERENCES
}

Alderman, D.H. 2008. Place, Memory and the Interception of Cultural Landscapes. In Graham B. and P. Howard (eds.): The Ashgate Research Companion to Heritage and Identity. Aldershot: Ashgate Publishing Limited.

Bauman, Z. 2000. Liquid Modernity. Oxford: Blackwell.

Henriksen, J.-O. \& O. Krogseth. 2001. Pluralisme og identitet. Oslo: Gyldendal.

Huyssen, A. 1995. Twilight Memories. New York: Routledge.

Lowenthal, D. 1985. The Past is a Foreign Country. Cambridge: Cambridge University Press.

\author{
AUTHOR CONTACT INFORMATION \\ Otto Krogseth \\ Department of Culture Studies and Oriental Languages \\ University of Oslo \\ Box 1010 Blindern \\ NO - 0315 Oslo \\ otto.krogseth@ikos.uio.no
}

